\title{
EXTENSIVE VISUAL LOSS WITH TOPICAL FACIAL STEROIDS
}

\author{
R. K. AGGARWAL ${ }^{1}$, T. POTAMITIS ${ }^{1}$, N. H. V. CHONG ${ }^{1}$, M. GUARRO ${ }^{2}$, P. SHAH ${ }^{1}$ and S. KHETERPAL ${ }^{1}$ \\ Birmingham and Redditch
}

\begin{abstract}
SUMMARY
Steroid creams applied topically to the skin are routinely used in the treatment of many dermatoses. Their use on the face in severe atopic eczema is relatively common. We report a series of three patients who whilst using topical facial steroids developed advanced glaucoma. A further two cases of ocular hypertension secondary to topical facial steroids are also described. This is the first series of cases to be reported demonstrating the potentially blinding complications of topical facial steroids. Recommendations are made with regard to screening such patients for glaucoma.
\end{abstract}

The risk of glaucoma with the use of topical steroid to the eye is well known. ${ }^{1-3}$ The risk associated with systemic steroids, although uncommon, has been described. ${ }^{4.5}$ Glaucoma developing secondary to the use of topical steroids to the face, first described in 1975 by Cubey, ${ }^{6}$ has attracted little attention; to our knowledge the literature contains only a few isolated case reports. ${ }^{7.8}$ The real risk of visual loss in young people who use steroid preparations to their face remains unrecognised. We describe the first series of patients who developed an elevation in intraocular presssure (IOP) secondary to the use of topical facial steroids. They presented between June 1991 and September 1992; three were found to have advanced glaucoma and a further two had ocular hypertension.

\section{CASE REPORTS}

\section{Case 1}

A 24-year-old Asian man presented with a history of blurred vision in the left eye. He had eczema involving the skin of the face including the eyelids and had been using $0.25 \%$ desoxymethasone cream on these areas for over 2 years. On examination unaided visual acuities were $6 / 5$ right and 6/60 left, with no improvement on refraction. He had a left relative afferent pupillary defect and the IOPs

\footnotetext{
From: 'Birmingham and Midland Eye Hospital, Birmingham; ${ }^{2}$ Alexandra Hospital, Redditch, Worcester, UK.

Correspondence to: R. K. Aggarwal, Birmingham and Midland Eye Hospital, Church Street, Birmingham B3 2NS, UK.
}

were $44 \mathrm{mmHg}$ right and $74 \mathrm{mmHg}$ left. On gonioscopy there was no angle abnormality, and both anterior chamber angles were wide open (Shaffer grade III to IV). Both optic discs exhibited extensive pathological cupping (cup/ disc ratio 0.8 right, 0.95 left). Goldman perimetry revealed marked glaucomatous visual field defects in both eyes, particularly on the left. On discontinuing the steroids and with the use of guttae timolol $0.5 \%$, the right IOP was controlled. The left eye, however, failed to respond to topical treatment, necessitating a trabeculectomy. Although this controlled the IOP, 12 months following presentation the patient was totally blind in his left eye.

\section{Case 2}

A 23-year-old Chinese man presented with a 6-month history of gradual visual loss affecting his left eye. He had severe atopic eczema of the periorbital skin, for which he had been using $1 \%$ hydrocortisone cream intermittently for about 12 years. On examination, with a myopic correction of $-6.75 \mathrm{D}$ sphere, visual acuities were $6 / 5$ right and $6 / 36$ left. His IOPs were $28 \mathrm{mmHg}$ right and $54 \mathrm{mmHg}$ left. He had a left posterior subcapsular cataract. There was no gonioscopic abnormality found and both anterior chamber angles were open (Shaffer grade III). On fundoscopy both optic discs were pathologically cupped (cup/disc ratio 0.6 right, 0.9 left). Goldman perimetry revealed extensive glaucomatous field loss in the left eye and an early arcuate scotoma in the right eye. With the discontinuation of the facial steroids and the use of guttae levobunolol $0.5 \%$, the right IOP was reduced to within normal limits. The left eye, however, failed to respond to topical treatment and eventually required a trabeculectomy to control the IOP.

\section{Case 3}

A 25-year-old Asian man presented with an 18-month history of gradual loss of vision in both eyes. He had severe atopic eczema involving the periorbital skin and had been applying various topical steroids, including $1 \%$ hydrocortisone, to this area for about 4 years. On examination, unaided visual acuities were 6/24 right and 6/18 left, 
with no improvement on refraction. His IOPs were $32 \mathrm{mmHg}$ right and $27 \mathrm{mmHg}$ left. In addition he had bilateral subcapsular cataracts. Gonioscopic examination was normal and both anterior chamber angles open (Shaffer grade III). Both optic discs were pathologically cupped (cup/disc ratio 0.6 right, 0.5 left). Goldman perimetry revealed early glaucomatous visual field defects in both eyes. On discontinuing the steroids to the face, and with the use of guttae timolol $0.5 \%$, both IOPs were reduced to normal levels.

\section{Case 4}

An atopic 13-year-old boy had been on $7.5 \mathrm{mg}$ systemic prednisolone on alternate days for some time. In addition he had been using $0.05 \%$ clobetasone buytyrate cream to his face and trunk, at least twice daily, for the past 12 years. On examination, unaided visual acuities were $6 / 5$ right and left. His IOPs, measured on three separate occasions, were between 26 and $30 \mathrm{mmHg}$ in both eyes. Gonioscopic examination was normal and both anterior chamber angles open (Shaffer grade III). His optic discs were healthy and Goldman perimetry visual fields were full. On discontinuing his topical facial steroids the IOP returned to normal despite the continued use of systemic steroids. The patient was then instructed to restart his topical medication, upon which his IOPs were again found to be elevated. Topical steroids were thus discontinued and his IOPs remain within normal limits.

\section{Case 5}

A 21 -year-old woman had been using $0.1 \%$ betamethasone cream three times per day for the past 10 years to control her facial eczema. On examination, unaided visual acuities were $6 / 6$ right and left. Her IOPs, tested on several occasions, were between 24 and $28 \mathrm{mmHg}$ in both eyes. Gonioscopic examination was normal and both anterior chamber angles open (Shaffer grade III). She had healthy discs and Goldman perimetry visual fields were full. Since discontinuing the topical facial steroids her IOPs have remained normal.

\section{DISCUSSION}

The phenomenon of steroid-induced glaucoma has been recognised since the early 1950s when McLean ${ }^{9}$ reported a rise in IOP secondary to the use of systemic adrenocorticotrophic hormone for the treatment of uveitis. Since then, it has been firmly established that certain patients are 'steroid responders', and develop a rise in IOP with the use of steroids. There is an increased incidence of this response in the presence of chronic open angle glaucoma $a^{2,10}$ or a family history of steroid responsiveness. ${ }^{11}$ In addition high myopes, ${ }^{12}$ diabetics, ${ }^{13}$ and patients with connective tissue disorders, ${ }^{14}$ are predisposed to steroid-induced glaucoma. Other steroid-induced ocular side effects, including cataracts and exacerbation of primary herpes simplex, are well documented in the literature. ${ }^{15}$

The majority of the publications describing steroidinduced glaucoma relate to the use of topical ophthalmic preparations. The few case reports associating glaucoma with facial steroids ${ }^{6-8}$ show that our cases are typical of those previously described. All of our patients are young and had been using topical facial steroids for many years. None of our patients had a family history of glaucoma or any ocular abnormality to account for their rise in IOP. Only one patient (case 4) was using systemic steroids, but despite this his IOP returned to normal on stopping his topical treatment, suggesting that this was the cause of the raised IOP. Marked elevations in IOP were tolerated without the occurrence of any symptoms. Therefore, patients did not present until advanced visual loss had occurred.

Although the phenomenon of steroid responsiveness is well established, it is not well known, particularly outside ophthalmological circles. This is especially true of steroids used on the face. In fact the British National Formulary gives no warning of glaucoma in its section on steroid preparations for the skin. The problem may be further compounded by the decision in 1987 to make steroid-containing preparations available without prescription. ${ }^{16}$ This could potentially lead to patients on long-term, unsupervised, self-medication with topical steroids. Another difficulty is that the use of topical steroids in facial eczema can lead to a dramatic and visible improvement in the patient's symptoms, making it very difficult to discontinue treatment. Furthermore, even if the steroids are stopped, the IOP may not return to normal.

Our cases illustrate that steroid preparations applied to the face can pose a real threat to the patient's vision. It is important, therefore, that patients on facial steroids be regularly reminded of the risk of glaucoma and advised to use their treatment sparingly. In addition patients should wash their hands after each application to avoid eye contamination with steroid cream. Patients on prolonged courses of facial steroids should be screened for glaucoma on a regular basis. This could be done by referring the patient to a suitably qualified ophthalmic practitioner for IOP measurements and optic disc assessment. If any abnormality is detected then a referral to an ophthalmologist would be appropriate.

The authors would like to thank Professor A. R. Fielder, Mr. E. C. O'Neill and Dr. W. Tucker for allowing them to report their patients.

Key words: Eczema, Eye, Facial, Glaucoma, Intraocular pressure, Topical steroids, Visual loss.

\section{REFERENCES}

1. Armaly MF. Effect of corticosteroids on intraocular pressure and fluid dynamics. I. The effect of dexamethasone in the normal eye. Arch Ophthalmol 1963;70:482-91.

2. Becker B, Mills DW. Corticosteroids and intraocular pressure. Arch Ophthalmol 1963;70:500-7.

3. Kitazawa Y. Increased intraocular pressure induced by corticosteroids. Am J Ophthalmol 1976;82:492-5.

4. Covell LL. Glaucoma induced by systemic steroid therapy. Am J Ophthalmol 1958;45:108-9.

5. Adhikary HP, Sells RA, Basu PK. Ocular complications of systemic steroids after renal transplantation and their association with HLA. Br J Ophthalmol 1982;66:290-1.

6. Cubey RB. Glaucoma following the application of cortico- 
steroids to the skin of the eyelids. Br J Dermatol 1976;95: 207-8.

7. Vie R. Glaucoma and amaurosis associated with long term application of topical corticosteroids to the eyelids. Acta Derm Venereol (Stockh) 1980;60:541-2.

8. Zugerman C, Sauders D, Levit F. Glaucoma from topically applied steroids. Arch Dermatol 1976;112:1326.

9. McLean JM. Use of ACTH and cortisone: discussion of paper of Woods AC. Trans Am Ophthalmol Soc 1950;48: 293-5.

10. Armaly MF. Effect of corticosteroids on intraocular pressure and fluid dynamics. II. The effect of dexamethasone in the glaucomatous eye. Arch Ophthalmol 1963;70:492-9.

11. Armaly MF. The heritable nature of dexamethasone- induced ocular hypertension. Arch Ophthalmol 1966;75: 32-5.

12. Podos SM, Becker B, Morton WR. High myopia and primary open-angle glaucoma. Am J Ophthalmol 1966;62: 1039-43.

13. Becker B. Diabetes mellitus and primary open-angle glaucoma. Am J Ophthalmol 1971;71:1-16.

14. Gaston H, Absolon MJ, Thurtle OA, Sattar MA. Steroid responsiveness in connective tissue diseases. $\mathrm{Br} \mathrm{J}$ Ophthalmol 1983;67:487-90.

15. Dahl MGC. Hazards of topical steroid therapy. Adverse Drug Reaction Bull 1985;115:428-31.

16. Edwards C, Stillman P. The use of topical hydrocortisone. Pharm J 1987;238:169-74. 